\title{
Survival of Colletotrichum dematium in Soil and Infected Mulberry Leaves
}

\author{
S. Yoshida and A. Shirata, National Institute of Sericultural and Entomological Sciences, 1-2 Owashi, Tsukuba, \\ Ibaraki 305-8634, Japan
}

\begin{abstract}
Yoshida, S., and Shirata, A. 1999. Survival of Colletotrichum dematium in soil and infected mulberry leaves. Plant Dis. 83:465-468.

Overwinter survival of Colletotrichum dematium, the causal agent of mulberry anthracnose, was examined in Japan. Conidia and infected mulberry leaves were mixed with soil and placed on the ground in early December. Viability of conidia declined rapidly under field conditions-they could not be recovered within 30 days - whereas conidia placed indoors or outdoors under a roof protected from rain and snow survived longer. When a suspension of soil infested with conidia was used to inoculate detached healthy leaves, no infection was detected after 65 days of incubation, suggesting that conidia in soil are not a significant form of overwintering inoculum. When infected or latently infected leaves incubated in soil under field conditions were used as inoculum on leaves, it was shown that the fungus remained viable for at least 150 days. The fungus in infected leaves maintained under laboratory conditions at different temperatures survived for at least 90 days at 25 and $35^{\circ} \mathrm{C}$ and for 600 days at $0^{\circ} \mathrm{C}$. These results suggest that C. dematium can overwinter in infected or latently infected leaves, and that these leaves can be a source of primary inoculum the following year. Hence, the elimination of fallen leaves in the field in autumn may be an effective way to prevent occurrence of the disease the following year.
\end{abstract}

Additional keyword: Morus

Mulberry, a woody plant belonging to the genus Morus, family Moraceae, is widely distributed in Japan. The leaves of the plant are used as feed for silkworms in the sericultural industry. Mulberry anthracnose was first reported in Japan in 1925 (5), and the causal pathogen was identified as Colletotrichum morifolium Hara. In a recent study (17), we reported that (i) anthracnose species isolated from diseased mulberry leaves were $C$. dematium, $C$. acutatum, and Glomerella cingulata, (ii) $C$. morifolium should be a synonym of $C$. dematium, and (iii) $C$. dematium was the most aggressive pathogen. Mulberry leaves infected with $C$. dematium displayed brown necrotic spots $(7,17)$, resulting in a decreased yield of leaves for silkworm feeding. The leaves with latent infection were a significant source of secondary inoculum (16).

We have confirmed the annual development of anthracnose caused by $C$. dematium in mulberry trees (15); initial disease symptoms develop on the foliage near the ground from late June to mid-July, and later in the season, the symptoms progress to the upper foliage. Based on these observations, we speculated that the fungus overwinters in the soil and infects newly

Corresponding author: Shigenobu Yoshida

E-mail: yoshige@ss.nises.affrc.go.jp

Accepted for publication 10 February 1999.

Publication no. D-1999-0301-02R

(C) 1999 The American Phytopathological Society emerging leaves near the ground the following year.

Overwinter survival of other anthracnose fungi, such as C. acutatum, C. coccodes, $C$. lindemuthianum, and $C$. truncatum, which infect strawberry (14), tomato (3), bean (11), and lentil (1), respectively, have been reported. Dillard and Cobb (2) demonstrated that the bean anthracnose fungus, $C$. lindemuthianum, overwintered 4 months in bean debris placed 0 to $20 \mathrm{~cm}$ deep in soil in New York State. Buchwaldt et al. (1) reported that several windborne materials-dust generated during harvest, plant debris, and soil-were sources of inoculum of $C$. truncatum, the cause of lentil anthracnose. In addition, survival of conidia and plant debris of some anthracnose fungi in soil has been reported to vary depending on environmental conditions, particularly on soil moisture and temperature $(4,9,13)$. In Japan, Ishikawa et al. (6) demonstrated that nit mutants of $C$. $a c u$ tatum, the causal fungus of strawberry anthracnose, survived in strawberry debris in winter, as well as in or on the plants. Thus, survival of several Colletotrichum species in soil has been demonstrated in detail; however, survival studies have not been conducted with the mulberry pathogen, $C$. dematium.

The objective of these experiments was to examine the possible sources of overwintering inoculum of $C$. dematium under field conditions. Studies focused on conidia in soil since the conidia play a significant role as secondary inoculum $(7,16)$ during the growing season. Tests were also conducted using infected leaves, since numerous mulberry leaves remain in the field through the following spring.

\section{MATERIALS AND METHODS}

Survival of conidia in soil (1995 tests). In December 1995, black volcanic ash soil (andosol) that was determined to be free of anthracnose pathogens was collected from a mulberry field at our institute. Prior to use, the soil was air-dried and sieved through a soil screen ( $8 \mathrm{~mm}$ opening) to remove large organic particles. Sieved soil was placed in two round plastic vessels 12 $\mathrm{cm}$ diameter and $7 \mathrm{~cm}$ high $(150 \mathrm{~g}$ per vessel). To eliminate the possible effect of other microorganisms on the survival of conidia, another sample of sieved soil sterilized by autoclaving $\left(121^{\circ} \mathrm{C}, 20 \mathrm{~min}\right)$ was placed in two vessels. Conidia of $C$. dematium (culture S8901) harvested from 10day-old mulberry leaf decoction-sucroseagar (MSA: dried mulberry leaf, $50 \mathrm{~g}$; sucrose, $30 \mathrm{~g}$; agar, $27 \mathrm{~g}$; distilled water, 1.5 liters) was suspended in sterilized distilled water (SDW). After adjustment of the concentration to $3 \times 10^{6}$ conidia per $\mathrm{ml}$ by hemacytometer, $20 \mathrm{ml}$ of the conidial suspension was added by atomizer to each vessel containing $150 \mathrm{~g}$ of natural or sterilized soil and mixed with a spatula. One inoculated vessel containing each type of soil was then placed outdoors on the ground approximately $200 \mathrm{~m}$ from the mulberry field, and another was kept indoors and maintained at 23 to $25^{\circ} \mathrm{C}$ in the dark. To determine conidia viability, a 0.2$\mathrm{g}$ soil subsample from each vessel was collected at 30-day intervals for 4 months, then at irregular intervals until 480 days after inoculation. Each subsample was suspended in $1.8 \mathrm{ml}$ of SDW and diluted in SDW to appropriate dilutions; then $0.5 \mathrm{ml}$ of a dilution was spread on a potatosucrose-agar (PSA) plate containing streptomycin (30 mg/liter). Two replicate plates were used per dilution. Plates were incubated at room temperature (23 to $26^{\circ} \mathrm{C}$ ), and colonies of $C$. dematium were counted after 5 days of growth. Number of viable conidia in each assay was evaluated based on the average number of colonies developing on two plates.

Survival of $C$. dematium in soil (1997 tests). In December 1997, each type of soil (natural or sterilized as described above) was placed on filter paper in two plastic petri dishes $(9 \mathrm{~cm}$ diameter) that were punctured in the bottom to remove excess water. A conidial suspension $(8 \mathrm{ml})$ containing $5 \times 10^{6}$ conidia of $C$. dematium per $\mathrm{ml}$ maintained as previously described was 
sprayed by atomizer onto natural or sterilized soil (30 g) in each dish and mixed with a spatula. One inoculated dish containing each type of soil was then placed at each of two locations as follows: outdoors on the ground approximately $200 \mathrm{~m}$ from the mulberry field as previously described, and outdoors under a roof protected from rain and snow. To determine conidia survival, a $0.2-\mathrm{g}$ soil subsample was collected from each dish at approximately 7-day intervals for 5 weeks, then at 14-day intervals until 107 days after inoculation. The number of viable conidia was determined by spreading a diluted suspension $(0.5 \mathrm{ml})$ on a PSA plate containing streptomycin and evaluating the number of viable conidia in each assay based on the average number of colonies developing on two plates. Results were subjected to Tukey's $q$ test at $P=0.05$. In addition, a suspension of the soil prepared by diluting $0.2 \mathrm{~g}$ of soil in $1.8 \mathrm{ml}$ of SDW was spread (approximately $1 \mathrm{ml}$ ) with an artist's brush on the abaxial surface of a cut mulberry leaf (approximately $4 \times 8 \mathrm{~cm}$ ) of the susceptible cultivar Ochii wounded with needles. Inoculated leaves were incubated for 5 to 10 days in moist chambers at room temperature. Fungus survival was determined by the development of anthracnose symptoms with acervuli and setae on the leaves. Symptomless leaves were also irradiated with UV rays (National GL-15 lamp, wavelength $253.7 \mathrm{~nm}$ ) according to Shirata's method (10) to determine if latent infections $(8,12)$ were present.
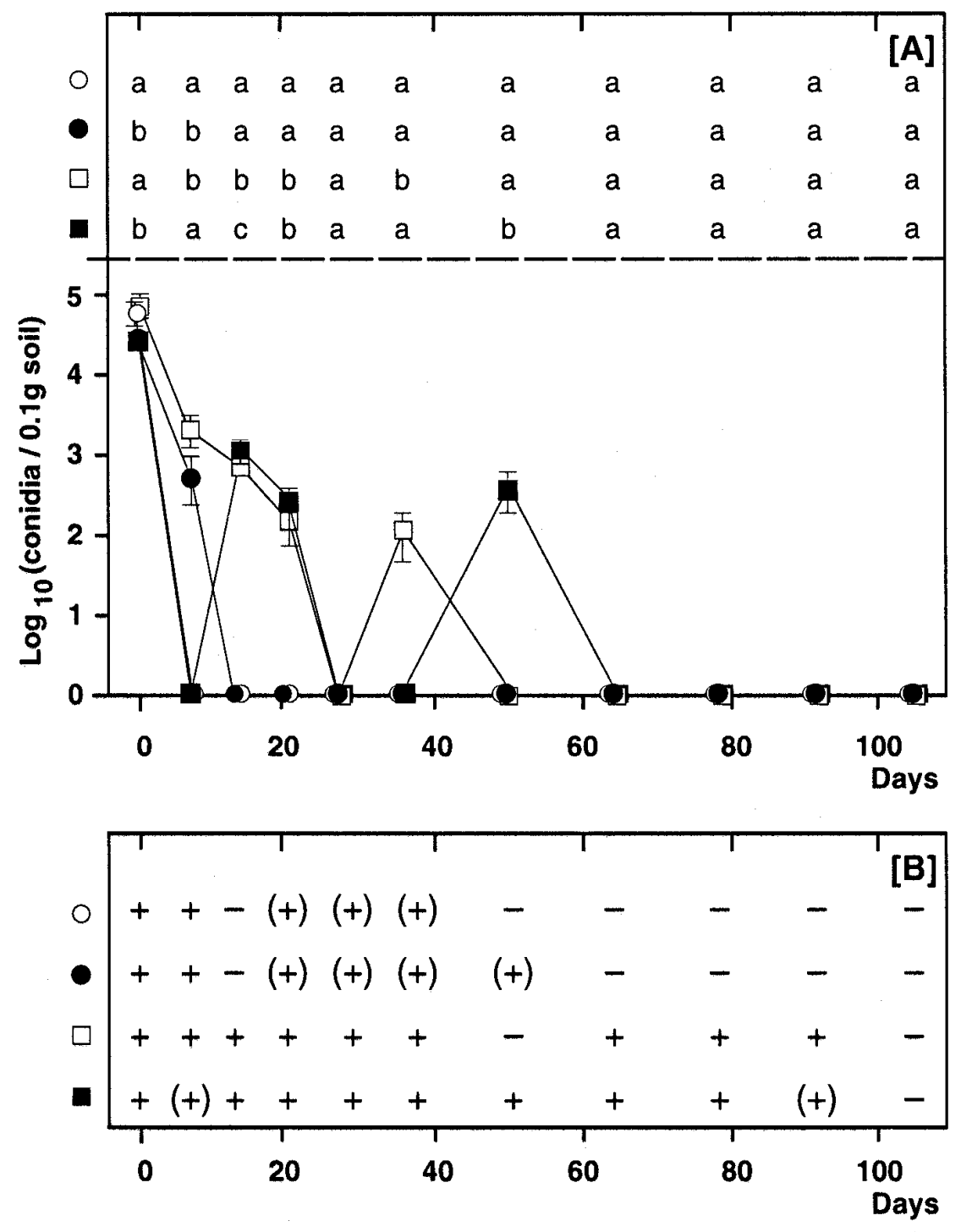

Fig. 1. Overwinter survival of conidia of Colletotrichum dematium S8901 in soil at two locations. (A) Number of viable conidia recovered from soil. The number in each assay was evaluated based on the average number of colonies on two replicate plates. Bars represent standard error of the mean. The same letters in each column are not significantly different $(P=0.05)$ according to Tukey's $q$ test. (B) Lesion formation on mulberry leaf with setae: +, detected; -, not detected. ( ) represents latent infections revealed by irradiation with UV rays. Symbols: $O$, in sterilized soil placed outdoors; $\bullet$, in nonsterilized soil placed outdoors; $\square$, in sterilized soil placed under the roof; $\square$, in nonsterilized soil placed under the roof.
Survival in infected mulberry leaves under laboratory conditions. Eight healthy mature mulberry leaves (cv. Ichinose) cultivated in the field were detached from shoots and inoculated by soaking in a conidial suspension $\left(10^{6}\right.$ conidia per $\left.\mathrm{ml}\right)$ of $C$. dematium prepared as described above. After incubation in moist chambers at room temperature until the development of symptoms (approximately 7 days), the inoculated leaves were air-dried and cut into 6 to $10 \mathrm{~cm}^{2}$ pieces with scissors. The cut leaves $(2 \mathrm{~g})$ were then covered with sterilized $\left(121^{\circ} \mathrm{C}, 20 \mathrm{~min}\right)$ soil in each petri dish (15 cm diameter). One dish was placed in each incubator at $0,5,10,15,20$, 25,30 , and $35^{\circ} \mathrm{C}$. Leaves were sampled from each dish at 30-day intervals for 120 days, then at irregular intervals through 600 days. Each recovered sample was divided into four pieces (approximately 1 $\mathrm{cm}^{2}$ ), which were placed on PSA plates after soaking in $70 \%$ ethanol for $30 \mathrm{~s}$; then $1,000 \mathrm{ppm}$ streptomycin $(10 \mu \mathrm{l})$ was applied to each sample. The fungus is able to tolerate this concentration of streptomycin. Survival was determined by the development of fungus colonies on the plates after incubation for 4 to 7 days at room temperature.

Survival in infected mulberry leaves under field conditions. This field test was carried out in December 1997. Thirty leaves (cv. Ichinose) infected with $C$. $d e$ matium were prepared as described above. They were then air-dried and cut into 6 to $10 \mathrm{~cm}^{2}$ pieces with scissors. The cut leaves $(15 \mathrm{~g})$ were placed into each of two cartons $(12 \times 24 \times 5 \mathrm{~cm})$ and mixed with sieved nonsterilized soil $(250 \mathrm{~g})$ by hand. After being covered with a nylon mesh bag, each carton was placed outdoors on the ground and outdoors under the roof, the same locations as the soil infected with conidia in 1997. Cut leaves $(15 \mathrm{~g})$ with latent infections were also prepared by drying them 2 days after inoculation, before the appearance of symptoms on the leaves, and placing them outdoors after mixing with soil in another carton as described above. Leaves buried in the soil were collected from each carton at 30-day intervals until May 1998. Viability of $C$. dematium in the leaf tissue was evaluated by two methods as follows: (i) Collected leaves were cut into small pieces (50 to 80 pieces) and then placed on PSA plates for colony development as described above. Results were subjected to ANOVA at $P=0.05$. (ii) Collected leaves $(0.5 \mathrm{~g})$ were placed in a conical tube (50 $\mathrm{ml})$. After the addition of SDW (30 ml), the leaves were homogenized with a Physcotron (Nichi-on-i Rika Kikai Ltd.) for 30 s. Leaf suspensions were then centrifuged at $400 \times g$ for $10 \mathrm{~min}$, and the supernatant was decanted. After the addition of 2 to 4 $\mathrm{ml}$ of SDW, a leaf pellet was spread with an artist's brush on a detached healthy mulberry leaf (cv. Ochii) that was wounded with needles. Survival was determined by 
the development of anthracnose symptoms with acervuli and setae on the leaves after incubation in moist chambers for 7 to 10 days at room temperature. Symptomless leaves were irradiated with UV rays as described above to reveal any latent infections.

\section{RESULTS}

Survival of conidia in soil $(1995$ tests). C. dematium was not recovered from the nonsterilized or sterilized soil located outdoors at the first sampling (30 days). Viable conidia were recovered through 180 days after inoculation in the sterilized soil incubated indoors. No viable conidia were detected from the infested nonsterilized soil that was incubated indoors. Common soil microorganisms, such as Fusarium spp. and Penicillium spp., and bacteria were frequently isolated from nonsterilized soil infested with $C$. dematium, making detection of the fungus difficult.

Survival of $C$. dematium in soil (1997 tests). Viable conidia were not recovered after 14 days of incubation in sterilized or nonsterilized soil incubated outdoors (Fig. 1A). When incubated outdoors under a roof, conidia in nonsterilized soil were recovered up to 51 days. At some sampling periods, the presence of $C$. dematium was masked by the growth of other soil microorganisms. Sterilized soil placed outdoors under the roof was predominantly contaminated by a Fusarium species in the middle of the test period, and $C$. dematium was not isolated after 28 days of incubation.

When leaves were inoculated with a suspension of infested soil, anthracnose lesions developed with samples collected after 51 days and 93 days of incubation outdoors (nonsterilized soil) and under the roof (nonsterilized and sterilized soil), respectively (Fig. 1B).

Survival in infected mulberry leaves under laboratory conditions. Length of survival of the fungus depended on the temperatures at which the inoculated mulberry leaves were incubated. The survival period tended to increase at lower incubation temperatures (Table 1). When infested leaves were incubated at $0^{\circ} \mathrm{C}$, the fungus was recovered for at least 600 days; whereas the fungus could not be recovered from leaves incubated at 25 and $35^{\circ} \mathrm{C}$ after 120 days of incubation.

Survival in infected mulberry leaves under field conditions. The fungus was detected on PSA medium for up to 90 days after burial (Table 2). The frequency of recovery from latently infected leaves placed outdoors was significantly $(P=$ 0.05) higher compared with that from symptomatic leaves, although the frequency varied at each sample period. At 120 days after burial, $C$. dematium was not recovered from the leaves, but other soil microorganisms were frequently isolated. However, suspensions of all infected leaves were pathogenic to healthy leaves even after 150 days of burial (until May 1998).

\section{DISCUSSION}

Based on the results of overwinter survival tests performed in 1995 and 1997, conidia of $C$. dematium have limited potential for survival in soil under natural conditions. In addition, inoculations with infested soil suspension did not induce the formation of anthracnose lesions after 65 days of incubation. Population levels of $C$. dematium at each recovery period from nonsterilized soil may not be accurate since other soil microorganisms masked the growth of the fungus. However, the population of this fungus in sterilized soil placed on the ground also declined rapidly (Fig. 1A). These results indicate that conidia of $C$. dematium have a low potential to overwinter in soil under field conditions and are not likely to be a significant primary source of inoculum in this region of Japan.

Survival periods of conidia in soil incubated indoors in 1995 or under the roof in 1997 were longer than those in soil incubated outdoors, suggesting that soil moisture may affect the viability of conidia. Vizvary and Warren (13) reported that survival of $C$. graminicola conidia was affected adversely by alternate drying and remoistening of soil. Soil moisture may also affect fungal survival in host plants; $\mathrm{Tu}$ (11) demonstrated that the survival of C. lindemuthianum in pod segments of white bean was reduced with alternating wet-dry cycles of soil. In addition, populations of $C$. acutatum conidia in laboratory soil tests steadily decreased under moist or

Table 1. Survival of Colletotrichum dematium S8901 in infected leaves at various temperatures ${ }^{\mathrm{a}}$

\begin{tabular}{|c|c|c|c|c|c|c|c|c|}
\hline \multirow[b]{2}{*}{ Days after incubation } & \multicolumn{8}{|c|}{ Incubation temperature $(\mathrm{C})$} \\
\hline & $\mathbf{0}$ & 5 & 10 & 15 & 20 & 25 & 30 & 35 \\
\hline 30 & $100^{\mathrm{b}}$ & 100 & 50 & 75 & 100 & - & 100 & 50 \\
\hline 60 & 100 & 75 & 100 & 100 & 100 & 75 & 100 & 50 \\
\hline 90 & 75 & 100 & 100 & 75 & 100 & 25 & 50 & 50 \\
\hline 120 & 100 & 50 & 75 & 50 & 75 & - & 50 & - \\
\hline 270 & 100 & 25 & - & 100 & - & - & - & - \\
\hline 390 & 100 & - & - & - & - & - & - & - \\
\hline 600 & 75 & - & - & - & - & - & - & - \\
\hline
\end{tabular}

${ }^{\text {a }}$ Four pieces of leaves were placed on potato-sucrose-agar (PSA) plates in each survey.

${ }^{\mathrm{b}}$ Frequency (\%) of recovery of $C$. dematium. -, not recovered.

Table 2. Overwinter survival of Colletotrichum dematium S8901 in infected leaves in soil

\begin{tabular}{|c|c|c|c|c|c|c|c|}
\hline \multirow[b]{2}{*}{ Location } & \multicolumn{7}{|c|}{ Days after burial } \\
\hline & $\mathbf{0}$ & 7 & 30 & 60 & 90 & 120 & 150 \\
\hline \multicolumn{8}{|l|}{ Recovery $(\%)$ of the fungus ${ }^{a}$} \\
\hline Outdoors & 4.7 & 3.3 & 0.0 & 32.9 & 0.0 & 0.0 & 0.0 \\
\hline Outdoors (latent infections) ${ }^{b}$ & 100.0 & 41.0 & 21.4 & 41.4 & 2.5 & 0.0 & 0.0 \\
\hline Under roof & 9.4 & 2.9 & 0.0 & 0.0 & 1.3 & 0.0 & 0.0 \\
\hline \multicolumn{8}{|l|}{ Lesion formation on leaves ${ }^{c}$} \\
\hline Outdoors & $++^{\mathrm{d}}$ & + & + & + & ++ & + & + \\
\hline Outdoors (latent infections) & ++ & ++ & + & ++ & + & +++ & + \\
\hline Under roof & ++ & ++ & + & + & $(+)$ & ++ & ++ \\
\hline
\end{tabular}

a 50 to 80 pieces of infected mulberry leaves were placed on potato-sucrose-agar (PSA) plates.

${ }^{\mathrm{b}}$ Latently infected leaves were placed outdoors on the ground.

${ }^{\mathrm{c}}$ Suspension of infected leaves was spread on punctured mulberry leaves.

${ }^{\mathrm{d}}$ Disease severity was classified based on area of anthracnose lesions appearing on leaves:,+ 1 to $30 \%$; ++, 31 to $50 \%$; +++, over $51 \%$. ( ) represents latent infections revealed by irradiation with UV rays. 
saturated conditions; whereas the conidia could be recovered for up to 12 months from inoculated soil under dry conditions (9). Similar results were obtained in this study for survival of conidia of $C$. dematium.

With many anthracnose fungi belonging to the Colletotrichum genus, it has been reported that plant debris such as leaves (9), roots $(3)$, and fruits $(3,14)$ are important sources of overwintering inoculum. In this study, $C$. dematium was able to survive long enough in diseased mulberry leaves under natural field conditions to provide inoculum to infect mulberry leaves the following season. We previously (15) reported that anthracnose symptoms caused by $C$. dematium were first observed on leaves located near the ground from late June to mid-July, which corresponds to the onset of the rainy season in the region. It is therefore likely that fungus-infested leaves that overwintered in the soil caused the initial infection on the leaves. Based on the longevity test of infected leaves under laboratory conditions at each fixed temperature, cooler temperatures increase the survival of the fungus. The survival test also revealed that the fungus could survive in latently infected leaves, suggesting that such leaves that fall in autumn may be a source of inoculum. Removal of fallen, symptomless leaves as well as symptomatic leaves from fields in autumn will contribute to prevention of the disease the following year.

\section{LITERATURE CITED}

1. Buchwaldt, L., Morrall, R. A. A., Chongo, G., and Bernier, C. C. 1996. Windborne dispersal of Colletotrichum truncatum and survival in infested lentil debris. Phytopathology 86:1193-1198.

2. Dillard, H. R., and Cobb, A. C. 1993. Survival of Colletotrichum lindemuthianum in bean debris in New York State. Plant Dis. 77:1233-1238.

3. Dillard, H. R., and Cobb, A. C. 1998. Survival of Colletotrichum coccodes in infected tomato tissue and in soil. Plant Dis. 82:235-238.

4. Eastburn, D. M., and Gubler, W. D. 1992. Effects of soil moisture and temperature on the survival of Colletotrichum acutatum. Plant Dis. 76:841-842.

5. Hara, K. 1925. Pathology of Practical Crops. Youkendo, Tokyo.

6. Ishikawa, S., Nakayama, K., Ohno, Y., and Ueno, S. 1994. Overwintering experiments with nitrate nonutilizing mutants of Colletotrichum acutatum, causal fungus of strawberry anthracnose. (Abstr.) Ann. Phytopathol. Soc. Jpn. 60:356.

7. Kimura, K. 1979. The Illustration of Mulberry Diseases in Japan. Kenpaksya, Tokyo.

8. Muirhead, I. F., and Deverall, B. J. 1981. Role of appressoria in latent infection of banana fruits by Colletotrichum musae. Physiol. Plant Pathol. 19:77-84.
9. Norman, D. J., and Strandberg, J. O. 1997. Survival of Colletotrichum acutatum in soil and plant debris of leatherleaf fern. Plant Dis. 81:1177-1180.

10. Shirata, A. 1993. Appearance of the lesion of anthracnose on the mulberry leaves by irradiation with ultraviolet light. Ann. Phytopathol. Soc. Jpn. 59:259-262.

11. Tu, J. C. 1983. Epidemiology of anthracnose caused by Colletotrichum lindemuthianum on white bean (Phaseolus vulgaris) in southern Ontario: Survival of the pathogen. Plant Dis. 67:402-404.

12. Verhoeff, K. 1974. Latent infections by fungi. Annu. Rev. Phytopathol. 12:99-110.

13. Vizvary, M. A., and Warren, H. L. 1982 Survival of Colletotrichum graminicola in soil. Phytopathology 72:522-525.

14. Wilson, L. L., Madden, L. V., and Ellis, M. A. 1992. Overwinter survival of Colletotrichum acutatum in infected strawberry fruit in Ohio. Plant Dis. 76:948-950.

15. Yoshida, S., and Shirata, A. 1998. Annua development of mulberry anthracnose caused by Colletotrichum dematium in relation to position of leaves in tree. Seric. Sci. Jpn. 67:327-332.

16. Yoshida, S., and Shirata, A. 1998. Severe infection of seedlings in a nursery bed caused by mulberry anthracnose fungus, Colletotrichum dematium. J. Seric. Sci. Jpn. 67:373379.

17. Yoshida, S., Shirata, A., Yoshida, S., and Kobayashi, T. 1995. Anthracnose fungi, Colletotrichum dematium, C. acutatum, Glomerella cingulata isolated from diseased mulberry leaves and their pathogenicity. Ann Phytopathol. Soc. Jpn. 61:75-81. 